\title{
MAPPING OF SCHISTOSOMA HEAMATOBIUM IN QENA DISTRICT, QENA GOVERNORATE, UPPER EGYPT; HOSPITAL-BASED STUDY By
}

ASMAA M. EL-KADY ${ }^{1}$, AHMED M. SEFELNASR ${ }^{2}$, DOAA MM. OSMAN ${ }^{3}$, MARWA K. KHAIRALLAH ${ }^{4}$, AMR H. ABOU FADDAN ${ }^{5}$ and MONA M. GABER ${ }^{6^{*}}$ Department of Medical Parasitology, Qena Faculty of Medicine ${ }^{1}$, South Valley University, Department of Geology, Faculty of Science ${ }^{2}$, Assiut University, Departments of Public Health and Community Medicine ${ }^{3}$, Internal Medicine ${ }^{4}$, Urology ${ }^{5}$, and Medical Parasitology ${ }^{6}$, Faculty of Medicine, Assiut University, Postal code, 71515.

Egypt (*Correspondence: monahadea@gmail.com, monagaber@med.aun.edu.eg ORCID: 0000-0002-1735-0168)

\begin{abstract}
Schistosoma haematobium infection is one of the most serious endemic parasites worldwide especially Africa. In Egypt, in spite of the control massive advances in reducing country-wide schistosomiasis prevalence rates; yet, endemic foci still exist. This study determined the percentage of positive urinary schistosomiasis cases among patients who complained from hematuria and or dysuria at Qena General Hospital and to conduct a spatial mapping of S. haematobium infection in Qena Governorate, Egypt.

A cross-sectional study was conducted at the Urology and Nephrology outpatient clinics at Qena General Hospital from January 2016 to December 2018. The subjects were permanent residents in Qena district who complained of either hematuria and/or dysuria $(\mathrm{N}=2371)$. The urine samples were subjected to full parasitological examinations. A detailed personal history was obtained after informed consent from them.

The results showed that 568/2371 (24\%) cases were positive for Schistosoma haematobium. The largest number of positive cases were recorded in autumn (44\%) followed by winter (35.2\%). Significantly higher odds ratios were among young male patients (less than 18 years) presented complaint in seasons other than summer, and lived in villages in the western bank of the River Nile. But apparently, higher number of infected cases was detected in eastern villages compared to western ones. Statistical analysis showed that living in the western area in Qena district was a risk factor for $S$. haematobium infection. It coincides with studying geological criteria of Qena district where western area is concave shape with slow water flow that allow more probability for snails' existence and consequently higher susceptibility for infection compared to convex shape of the eastern area.
\end{abstract}

Keywords: Schistosoma haematobium; Qena District; Hematuria; Dysuria; Spatial Pattern.

\section{Introduction}

Schistosomiasis is a parasitic disease caused by the digenetic trematodes of the genus Schistosoma members which are commonly known as blood flukes. Schistosomiasis is the third-leading endemic parasitic disease in the world after malaria and amoebiasis (Okwori et al, 2014). WHO (2019) estimated that 220.8 million people infected with schistosomiasis in 78 countries.

Schistosomiasis whether intestinal (S. mansoni) or urinary (S. haematobium) types is parasitic trematode, acquired by contact with water containing infective cercariae. Schistosoma species are widely distributed mainly African and Asian countries (WHO, 2016).
S. haematobium was the first blood fluke worldwide discovered by Theodor Maximillian Bilharz (1851) a German physician at el-Kasr el-Aini Hospital in Cairo recovered the adult fluke from a dead soldier (Bilharz, 1852). S. haematobium infects the urinary tract, causing urinary schistosomiasis, and is the leading cause of bladder cancer, only next to tobacco smoking (Berry et al, 2017). Also, it contributed to HIV (Leutscher et al, 2005). S. haematobium completes it life cycle in humans, as definitive hosts, and freshwater snails belonging to the genus Bulinus, including $B$. globosus, B. forskalii, B. nasut$u s, B$. nyassanus, and $B$. truncatus act as intermediate host(s) and can harbor the miraci- 
dia (Rollinson et al, 2001). The emerged cercariae are short lived swimming infective stage and can survive in water for 4-6 days unless they find man (Sarant, 2017). The intensity of infection is affected by the frequency and duration of contact with infected water. Factors such as age, sex, occupation, education level, socioeconomic status, and residence influence a person's contact with contaminated water (Abou-El-Naga, 2018).

Although successful control projects have been implemented in the last 50 years, yet neither the number of endemic countries nor the estimated number of people infected or at risk of infection was reduced (Barakat, 2013). On the contrary, new diseases foci and acute outbreaks are observed worldwide. In Egypt, control efforts have made massive advances in reducing country-wide prevalence rates from near $40 \%$ in the early half of the 20th century to be around $1 \%$ in 2010; yet, endemic foci still exist (Rollinson et al, 2013). However, the absence of accurate epidemiological data to determine the possible burden of schistosomiasis infection leads to the failure of national control programs toward achieving maximum benefits and reaching complete elimination.

The present study aimed to evaluate the positive rate of Schistosoma haematobium among patients complained of hematuria and or dysuria and to conduct a spatial mapping of $S$. haematobium infection in Qena District, Qena Governorate, Egypt.

\section{Material and Methods}

Study area: The study was carried out in Qena General Hospital, Qena Governorate.

Qena Governorate locates in the southern part of Egypt. It covers a stretch of the Nile Valley. It lies $26^{\circ} 10^{\prime} 12^{\prime \prime} \mathrm{N} 32^{\circ} 43^{\prime} 38^{\prime \prime} \mathrm{E}$ and covers an area of $384.9 \mathrm{~km} 2$ distributed on 17 rural villages on both west and east Nile river banks. It is $75 \mathrm{~m}$ (246 feet) elevated over sea level. It has a total population of 230,392 inhabitants. Residents of Qena engage in farming as their primary economic activity for life (Figs. $1 \& 2$ ).
Study design: A cross-sectional study was conducted at the Urology and Nephrology outpatient clinics in Qena General Hospital in the period from January 2016 to December 2018. The study targeted to the permanent residents in Qena District $(n=2371)$ who complained of hematuria and/or dysuria and attended to those outpatient clinics.

Ethical consideration: All procedures followed were in accordance with the standard ethical of the responsible committee on human studies (Assiut University). Besides, the present study was approved (No. 17300366) by the Ethics Committee of Faculty of Medicine, Assiut University. Written informed consents were taken from all participants above 18 years old or from the parents who was below 18 years old.

Parasitological examination: The morning urine samples were collected a clean labeled container for examination (Garcia, 2001). Briefly, $10 \mathrm{ml}$ of urine was aliquoted using disposable syringes and filtered via a polycarbonate filter membrane. The filters measured $25 \mathrm{~mm}$ in diameter with a pore size of $12 \mu \mathrm{m}$ (Whatman, Kent, UK). The filtrates were placed on labeled microscope glass slides with subsequent reading three direct smears from one urine specimen. The patient was considered to be positive if at least one egg was observed on microscopic examination of urine (Garcia and Bruckner, 2001).

Spatial analysis: The generation of maps and the spatial analysis of samples were done using ArcGIS Software (ArcMap 10.5).

Statistical analysis: Data analysis was conducted by using SPSS program version 16. Qualitative data were presented in frequencies and proportions, while mean and standard deviation were used to express quantitative data. Univariate and multivariable logistic regression identified the predictors of $S$. haematobium infection. Odds ratio was reported with the corresponding 95\% confidence intervals and probability value. Statistical significance was considered when 
$P$ value was less than 0.05 and $95 \%$ confi dence intervals did not overlap.

\section{Results}

Out of 2371 patients complained of hematuria $(84.3 \%)$ or dysuria (15.7), and sought health care at Qena General Hospital; 568 cases (24\%) had S. haematobium (Fig. 3). They were from 13 villages in Qena District on both sides of the Nile River (Fig. 4). The mean age of $S$. haematobium patients
$(15.19 \pm 6.28)$ was less than the non-infected ones $(24.85 \pm 16.87)$. Males were higher than females as to positive infection or negative ones. The majority was Qena Eastern residents compared to western one regarding positive and/or negative infections, with highest number of $S$. haematobium patients was in autumn (44\%) followed by winter (35.2\%).

The detailed results were given in tables (1 $\& 2)$ and figures $(1,2,3,4 \& \% 5)$.

Table 1: Criteria of the studied population in Qena district, Qena Governorate; Upper Egypt 2016-2018.

\begin{tabular}{|l|c|c|c|}
\hline & Positive cases $(\mathrm{n}=568)$ & Negative cases $(\mathrm{n}=1803)$ & Total $(\mathrm{n}=2371)$ \\
\hline Age $($ mean \pm SD) & $15.19 \pm 6.28$ & $24.85 \pm 16.87$ & $22.54 \pm 15.58$ \\
\hline Male & $490(86.3 \%)$ & $1081(60.0 \%)$ & $1571(66.3 \%)$ \\
\hline Female & $78(13.7 \%)$ & $722(40.0 \%)$ & $800(33.7 \%)$ \\
\hline Complaints & & & \\
\hline Hematuria & $489(86.1)$ & $1509(83.7)$ & $1998(84.3)$ \\
\hline dysuria & $79(13.9)$ & $294(16.3)$ & $373(15.7)$ \\
\hline Month & & & \\
\hline Summer & $42(7.4 \%)$ & $391(21.7 \%)$ & $433(18.3 \%)$ \\
\hline Autumn & $250(44.0 \%)$ & $744(41.3 \%)$ & $994(41.9 \%)$ \\
\hline Winter & $200(35.2 \%)$ & $329(18.2 \%)$ & $529(22.3 \%)$ \\
\hline Spring & $76(13.4 \%)$ & $339(18.8 \%)$ & $415(17.5 \%)$ \\
\hline Residence & & & \\
\hline East & $368(64.8 \%)$ & $1282(71.1 \%)$ & $1650(69.6 \%)$ \\
\hline Abnud & $0(0 \%)$ & $12(0.9 \%)$ & $12(0.7 \%)$ \\
\hline Al Ashraf El Bahreia & $0(0 \%)$ & $56(4.4 \%)$ & $56(3.4 \%)$ \\
\hline Al Ashraf El Kabalea & $11(3.0 \%)$ & $72(5.6 \%)$ & $83(5.0 \%)$ \\
\hline Awlad Amr & $91(24.7 \%)$ & $156(12.2 \%)$ & $247(15.0 \%)$ \\
\hline Al Gabalaw & $0(0 \%)$ & $55(4.3 \%)$ & $55(3.3 \%)$ \\
\hline Al Hujirat & $58(15.8 \%)$ & $153(11.9 \%)$ & $211(12.8 \%)$ \\
\hline Qena & $208(56.5 \%)$ & $758(59.1 \%)$ & $966(58.5 \%)$ \\
\hline Karam Omran & $0(0 \%)$ & $20(1.6 \%)$ & $20(1.2 \%)$ \\
\hline West & $200(35.2 \%)$ & $521(28.9 \%)$ & $721(30.4 \%)$ \\
\hline Al Taramsa & $46(23.0 \%)$ & $50(9.6 \%)$ & $96(13.3 \%)$ \\
\hline Al Dir Al Sharqy & $0(0 \%)$ & $94(18.0 \%)$ & $94(13.0 \%)$ \\
\hline Al Tuwayrat & $12(6.0 \%)$ & $68(13.1 \%)$ & $80(11.1 \%)$ \\
\hline Al Mahrosa & $22(11.0 \%)$ & $58(11.1 \%)$ & $80(11.1 \%)$ \\
\hline Dandara & $120(60.0 \%)$ & $251(48.2 \%)$ & $371(51.5 \%)$ \\
\hline
\end{tabular}

Table 2: Predictors of Schistosoma infection in Qena district, Qena Governorate; Upper Egypt 2016-2018.

\begin{tabular}{|l|l|c|c|c|c|c|c|}
\hline \multicolumn{2}{|c|}{ Variable } & \multicolumn{3}{|c|}{ Unadjusted } & \multicolumn{3}{c|}{ Adjusted } \\
\cline { 3 - 8 } \multicolumn{2}{|c|}{} & Odds ratio & $95 \% \mathrm{CI}$ & $\mathrm{P}$-value & Odds ratio & $95 \% \mathrm{CI}$ & P-value \\
\hline Age & $<18$ versus 18years or more & 4.46 & $3.62 \pm 5.49$ & $\mathrm{P}<0.001$ & 4.69 & $3.76 \pm 5.85$ & $\mathrm{P}<0.001$ \\
\hline Sex & Male versus female & 4.20 & $3.25 \pm 5.42$ & $\mathrm{P}<0.001$ & 4.12 & $3.15 \pm 5.41$ & $\mathrm{P}<0.001$ \\
\hline Residence & Western versus Eastern & 1.34 & $1.10 \pm 1.63$ & 0.004 & 1.36 & $1.09 \pm 1.70$ & 0.007 \\
\hline \multirow{3}{*}{ Season } & Autumn versus Summer & 3.13 & $2.2 \pm 4.44$ & $\mathrm{P}<0.001$ & 3.26 & $2.26 \pm 4.71$ & $\mathrm{P}<0.001$ \\
\cline { 2 - 8 } & Winter versus Summer & 5.66 & $3.93 \pm 8.14$ & $\mathrm{P}<0.001$ & 6.35 & $4.31 \pm 9.36$ & $\mathrm{P}<0.001$ \\
\cline { 2 - 8 } & Spring versus Summer & 2.09 & $1.39 \pm 3.13$ & $\mathrm{P}<0.001$ & 2.06 & $1.34 \pm 3.15$ & 0.001 \\
\hline
\end{tabular}

Large positive $S$. haematobium patients were in November (92 cases), followed by December (85 cases), January (75 cases), October ( 73 cases) and February ( 70 cases).

In the univariate and multivariable logistic regression models, cases aged less than 18 years had a significantly higher risk for in- fection. Males were significantly more susceptible to infection compared to females. Residence in the western area in Qena distri ct had a significantly higher odds ratio compared to Eastern residence. The positive cases in autumn, winter, and spring significantly increased the $S$. haematobium probability. 


\section{Discussion}

Generally, schistosomiasis haematobium is one of the neglected tropical diseases.

In the present study, S. haematobium was positive in 568/2371 (24\%) among Qena District residents who suffered from hematuria or dysuria and sought health care at Qena General Hospital. Spot mapping of Schistosomiasis cases showed that they were living in 13 villages on both sides of the River Nile. The infection rate was higher than given by Sayed et al. (2014) who conducted a hospital-based study in Qena General Hospital and rerecorded $13.9 \%$ infection rate (Sayed et al, 2014). The higher proportion of positive infection in the current study is an alarming sign of the reemergence of $S$. haematobium infection in Qena governorate. A community-based study was needed to assess the ongoing infection status and consequently reformed the authorities of control Qe na Governorate of $S$. haematobium measures (Hammam et al, 2000a) There was a wide gap of knowledge on the epidemiology of $S$. haematobium in Qena as the last large scale representative study was conducted nearly twenty years ago and lower prevalence rates of infection were reported by communitybased studies in Upper Egypt Governorates. The overall estimated prevalence rates were $4.8 \%, 5.21 \%$, and $8.8 \%$ in Qena, Assuit and El Minya Governorates respectively (Hammam et al, 2000b; Gabr et al, 2000).

In the present study, the hospital-based nature of schistosomiasis may explain the higher positive infection rate detected compared to the prevalence rates reported by different studies performed on Qena Governorate and other ones in Upper Egypt.

The preset result of age- and sex-specific patterns of $S$. haematobium patients showed typical peak incidence in early adult males which may be attributed to higher frequency contact with contaminated water, as they were involved in agricultural activities such as irrigation, farming, fishing, swimming ...etc. This fact agreed with both El-Khoby et al. (2000) and Sayed et al. (2014).
In the present study, prevalence infection rates varied seasonally. Winter, autumn, and spring showed the highest peak flow as reported by Hussein and Bin-Dajem (2008). Higher infection rates in seasons other than summer may be attributed to contact of patients with water in hot weather and presentation of infection in cold seasons after the appearance of the infective bifurcate cercariae of schistosomiasis haematobium. Besides, this fact could be related the $S$. haematobi$u m$ intermediate snails population behavior in Qena Governorate, where their densities varied seasonally with the peak was occured in Autumn (Hussein et al, 2011).

Many other factors could affect the density of snails and subsequently the probability of infection. These include physical factors such as water current (Ofoezie, 1999). The flow velocity of the River Nile ranges from 0.8 to $1.3 \mathrm{~m} / \mathrm{s}$ with an average gradient of about $10 \mathrm{~cm} / \mathrm{km}$. However, Qena exposes the greatest bens of the River Nile. This bend affects, in turn, the flow velocity as well as the flow direction of the water in the Nile course, as the water flows much slower along the concave side of the river (western villages). Consequently, those spots would be much vulnerable to host Schistosomiasis and people who are in liaison with those spots would be prone to infection. Residents in eastern Nile river villages have an apparently higher proportion of infection was compared to those in residing western areas., However, residing in the western area in Qena District was a risk factor for infection with $S$. haematobium.

The Egypt's national schistosomiasis control measures mostly focused on Middle-Upper Egyptian Governorates (El-Khoby et al, 2000). They secured about two million irrigated Feddans with a total population of more than 12 million people (Barakat, 2013). So, there was a consistent reduction in the prevalence of $S$. haematobium in these governorates except in the most Southern Governorates, Sohag, Qena, and Aswan (El-Khoby et al, 2000). Barakat (2013) reported that 
these governorates gave a dramatic increase in $S$. haematobium prevalence due to conversion to the perennial irrigation system.

Qena Governorate is an agricultural community depends on the perennial irrigation by main River Nile body and distributary canals, which increased the $S$. haematobium infection risk due to permanent water contact. Community-based field study is a must to clarify the $S$. haematobium epidemiology in Qena Governorate in front of the Health Authorities.

\section{Conclusion}

Mapping of $S$. haemtobium in Qena District showed a high percentage of positive cases with high probability for infection in the western Nile River bank villages, compared to the eastern ones. High infection rate indicated the need of large scale survey of $S$. haematobium in Qena Governorate i9n collaboration with the Egyptian Authorities of National Schistosomiasis Control program.

Conflict of Interest: There was no conflict of interests to disclose.

\section{Acknowledgement}

This paper was kindly funded by a grant from South Valley University, Egypt

\section{References}

Abou-El-Naga, IF, 2018: Towards elimination of schistosomiasis after 5000 years of endemicity in Egypt. Acta Trop. 181:112-21.

Barakat, RM, 2013: Epidemiology of schistosomiasis in Egypt: Travel through time: Review. J. Adv. Res. 4:425-32.

Berry, A, Iriart, X, Fillaux, J, Magnaval, JF, 2017: Urinary schistosomiasis and cancer. Bull. Soc. Pathol. Exot. 110, 1:68-75

Bilharz, T, 1852: Fernere Mittheilungen uber Distomum haematobium. Zeitsch. Wissenschaft. Zool. 4:454-6.

El-Khoby, T, Galal, N, Fenwick, A, Barakat, R, El-Hawey, A, et al, 2000: The epidemiology of schistosomiasis in Egypt: Summary findings in nine governorates. Am. J. Trop. Med. Hyg. 62:88-99.

Gabr, NS, Hammad, TA, Orieby, A, Shawky, E, Khattab, MA, et al, 2000: The epidemiology of schistosomiasis in Egypt: Minya Governorate. Am. J. Trop. Med. Hyg. 62:65-72. Garcia, L, Bruckner, D, 2001: Intestinal prot- ozoa: coccidia and microsporidia. In: Diagnostic Medical Parasitology, $4^{\text {th }}$ ed. American Society of Microbiology, Washington.

Hammam, HM, Allam, FA, Moftah, FM, Abdel-Aty, MA, Hany, AH, 2000a: The epidemiology of schistosomiasis in Egypt: Assiut Governorate. Am. J. Trop. Med. Hyg. 62:73-9.

Hammam, HM, Zarzour, AH, Moftah, FM, Abdel-Aty, MA, Hany, AH, 2000b: The epidemiology of schistosomiasis in Egypt: Qena governorate. Am. J. Trop. Med. Hyg. 62:80-7.

Hussein, AN, Dajem, S, 2008: Prevalence of urinary schistosomiasis and infections with trematode larval stages in Bulinus truncatus snails from Qena Upper Egypt. J. Appl. Sci. Res. 416: 10-7.

Hussein, MA, Obuid-Allah, AH, Mahmoud, A A, Fangary, HM, 2011: Population dynamics of freshwater snails (Mollusca: Gastropoda) at Qena Governorate, Upper Egypt. Egypt. Acad. J. Biol. Sci. B. Zool. 3:11-22.

Leutscher, PD, Pedersen, M, Raharisolo, C, et al, 2005: Increased prevalence of leukocytes and elevated cytokine levels in semen from Schistosoma haematobium-infected individuals. J. Infect. Dis. 191, 10:1639-47.

Ofoezie, IE, 1999: Distribution of freshwater snails in the man-made Oyan Reservoir, Ogun State, Nigeria. Hydrobiologia 416:181-91.

Okwori, A, Sidi, M, Ngwai, Y, Obiekezie, S, Makut, M, et al, 2014: Prevalence of schistosomiasis among primary school children in Gadabuke District, Toto LGA, North Central Nigeria. Br. Microbiol. Res. J. 4:255-61.

Rollinson, D, Knopp, S, Levitz, S, Stothard, JR, Tchuente, LA, et al, 2013: Time to set the agenda for schistosomiasis elimination. Acta. Trop. 128:423-40.

Rollinson, D, Stothard, JR, Southgate, VR, 2001: Interactions between intermediate snail hosts of the genus Bulinus and schistosomes of the Schistosoma haematobium group. Parasitology 123:S245-60.

Sarant, L, 2017: Egypt: The flatworm's revenge. Nature 551, 7679:S46-7.

Sayed, FG, Alsalahy, M, Abd-El-Kader, MS, Abdalla, OH, Ahmed, SS, 2014: Prevalence of schistosomiasis among patients attending Qena General Hospital over the years 2011 \& 2012. J. Egypt. Soc. Parasitol. 44, 2:489-95.

WHO, 2016: Schistosomiasis and soil-transmitted helminthiases: number of people treated in 2015: Weekly Epidemiological Record. Wld. Hl 
th. Org. 91:585-600.

WHO, 2019: Schistosomiasis. Geneva: Availa-

ble: https://www.who.int/news-room/fact-sheets/ detail/ schistosomiasis.

\section{Explanation of figures}

Fig. 1: A satellite image (MrSID, horizontal resolution: $250 \mathrm{~m}$.) showed orientation, main cities and villages and main water channels. Fig. 2: A map showed population distribution in cities and villages studied.

Fig. 3: S. haematobium infection among patients with either hematuria or dysuria, Qena district, Qena Governorate, $2016-2018$.

Fig. 4: A satellite image (MrSID, horizontal resolution: $250 \mathrm{~m}$.) showed distribution of positive cases in villages on both eastern and western sides of River Nile.

Fig. 5: Distribution of presented Schistosoma cases by months Qena district, Qena governorate; upper Egypt 2016-2018
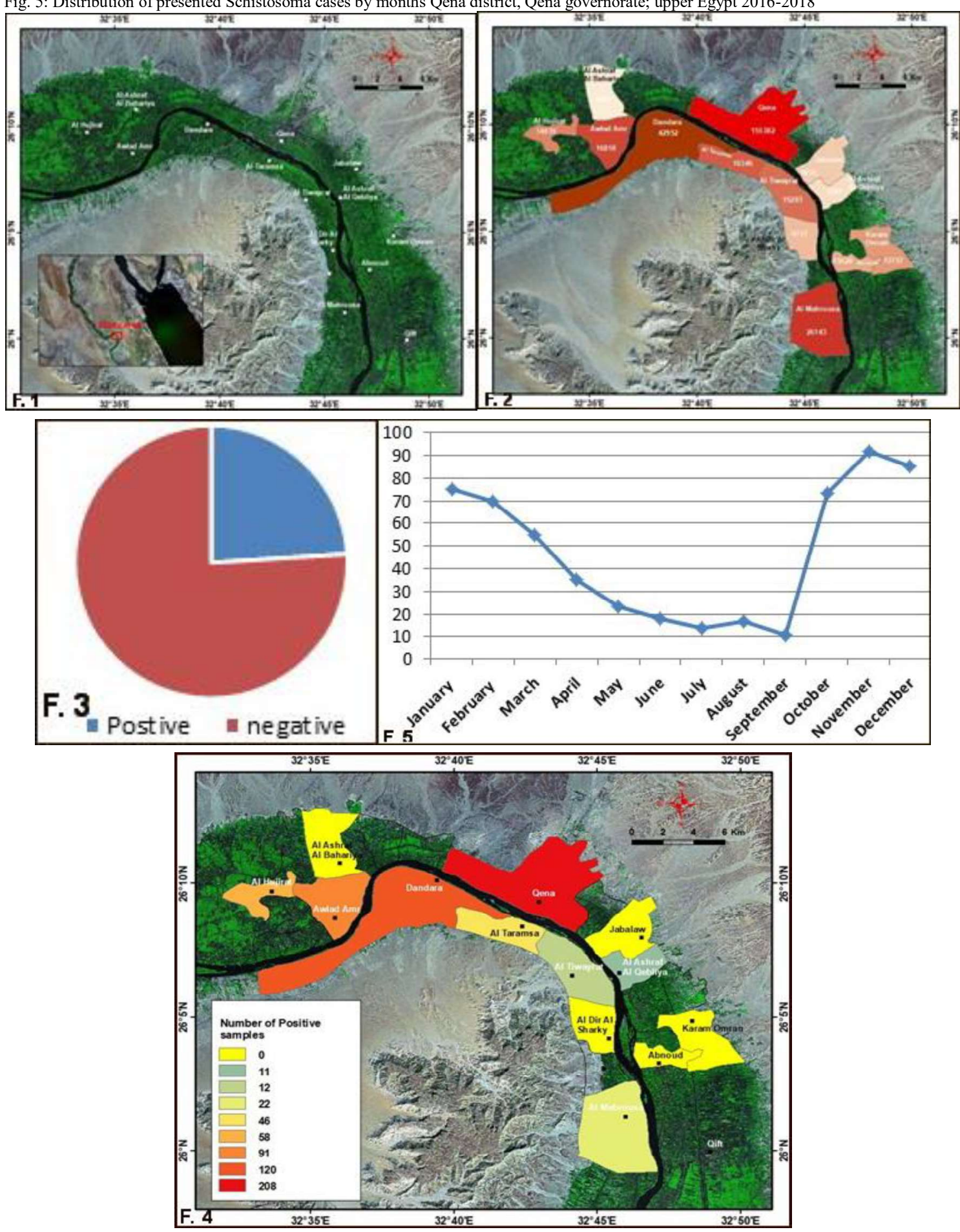